\title{
Effectiveness of traditional Chinese medicine in treating gastrointestinal dysfunction in patients with acute stroke: a systematic review and meta-analysis of 16 randomized controlled trials
}

\author{
Yan-Xin Wang ${ }^{1 \#}$, Lu-Ting Wang ${ }^{1 \#}$, Zong-Wen Huang ${ }^{2}$, Tian-Lun Li ${ }^{2}$, Xiao-Fang Ouyang ${ }^{2}$ \\ ${ }^{1}$ Department of Neurosurgery, The First Affiliated Hospital of Hainan Medical University, Haikou, China; ${ }^{2}$ Department Traditional Chinese \\ Medicine, The First Affiliated Hospital of Hainan Medical University, Haikou, China \\ Contributions: (I) Conception and design: YX Wang; (II) Administrative support: XF Ouyang; (III) Provision of study materials or patients: LT Wang, \\ TL Li; (IV) Collection and assembly of data: ZW Huang; (V) Data analysis and interpretation: YX Wang; (VI) Manuscript writing: All authors; (VII) \\ Final approval of manuscript: All authors. \\ \#These authors contributed equally as co-first authors. \\ Correspondence to: Xiao-Fang Ouyang. Department Traditional Chinese Medicine, The First Affiliated Hospital of Hainan Medical University, \\ Haikou 570102, China. Email: ouyangxiaofang1053@163.com.
}

\begin{abstract}
Background: Gastrointestinal dysfunction is one of the complications after stroke. If it is not treated in time, it will affect the rehabilitation process after stroke and reduce the quality of life of patients. In this study, we conducted a systematic review and meta-analysis of the reports on the treatment of gastrointestinal dysfunction after stroke with traditional Chinese medicine (TCM) in recent years to provide evidence for clinical diagnosis and treatment.
\end{abstract}

Methods: The clinical randomized controlled trials (RCTs) published in Chinese Biomedical Literature Database (CBM), China National Knowledge Infrastructure (CNKI), Medline, and Web of Science databases from January 2010 to August 2021 were searched. After screening the qualified literatures, literature quality evaluation was performed. The software Stata 16.0 was used to analyze and compare the outcome indicators of TCM and conventional western medicine treatment, and the utility of TCM in the treatment of gastrointestinal disorders after stroke was comprehensively evaluated.

Results: A total of 16 studies were finally selected including a total of 1,589. Meta-analysis showed that TCM treatment of gastrointestinal disorders after stroke was more effective than conventional western medicine treatment [odds ratio $(\mathrm{OR})=3.94 ; 95 \%$ confidence interval $(\mathrm{CI}): 2.63$ to $5.89 ; \mathrm{P}=0.000$ ]. It was also shown that TCM can reduce the recovery time of bowel sounds and is superior to conventional western medicine [standard mean difference $(\mathrm{SMD})=-1.92 ; 95 \% \mathrm{CI}:-2.51$ to $-1.34 ; \mathrm{P}=0.000$ ]; reduce defecation and flatulence recovery time $(\mathrm{SMD}=-2.51 ; 95 \% \mathrm{CI}:-3.41$ to $-1.61 ; \mathrm{P}=0.000)$; increase gastrin level $(\mathrm{SMD}=0.80$; 95\% CI: 0.35 to $1.25 ; \mathrm{P}=0.001$ ); increase motilin level ( $\mathrm{SMD}=2.27 ; 95 \% \mathrm{CI}: 1.55$ to $3.00 ; \mathrm{P}=0.000$ ); increase serum albumin level ( $\mathrm{SMD}=0.72 ; 95 \% \mathrm{CI}$ : 0.54 to $0.90 ; \mathrm{P}=0.000)$; increase transferrin levels $(\mathrm{SMD}=1.11$; 95\% CI: 0.86 to $1.36 ; \mathrm{P}=0.000$ ); and it can increase serum prealbumin levels ( $\mathrm{SMD}=1.50 ; 95 \% \mathrm{CI}: 0.78$ to 2.22; $\mathrm{P}=0.000)$.

Discussion: The use of TCM in the treatment of gastrointestinal dysfunction after stroke can effectively reduce symptoms, shorten the recovery time of bowel sounds, the first defecation and flatulence time, promote gastric motility and gastrointestinal hormone secretion, and improve the nutritional status of patients.

Keywords: Traditional Chinese medicine (TCM); stroke; gastrointestinal disorders; meta-analysis

Submitted Sep 22, 2021. Accepted for publication Nov 12, 2021.

doi: 10.21037/apm-21-2915

View this article at: https://dx.doi.org/10.21037/apm-21-2915 


\section{Introduction}

Acute stroke may be followed by complications such as pulmonary infection, urinary tract infection, malnutrition, and stress injury (1). Gastrointestinal dysfunction is one of the common complications, due to cerebrovascular disease caused by nervous system disorders, leading to abnormal nutritional absorption, energy metabolism disorders, vomiting, diarrhea, constipation, and other symptoms (2). A delay in intervention can further exacerbate malnutrition, cause endocrine disorders, decrease immune function, destroy the patient's physical internal environment, and increase the risk of infection, which is not conducive to subsequent treatment and rehabilitation (3). Traditional western medicine mostly provides symptomatic treatment with gastrointestinal prokinetic agents, mucosal protective agents, and probiotics; contrastingly, traditional Chinese medicine (TCM) has accumulated a wealth of experience in the treatment of gastrointestinal reactions, and some studies have suggested that the effect of TCM treatment is better than that of western medicine (4). Traditional Chinese medicine believes that the most common TCM Syndromes of secondary gastrointestinal disorders in patients with acute stroke are phlegm heat accumulating in the spleen, gastrointestinal heat accumulating and liver Qi invading the stomach, while the disorder of Qi mechanism and imbalance of rise and fall are the main pathogenesis (5). There are many clinical studies on the treatment of secondary complications after stroke with traditional Chinese medicine, but there is a lack of effective systematic evaluation on the treatment of gastrointestinal disorders after stroke with traditional Chinese medicine (6). In order to provide stronger evidence-based medical support, this study screened randomized controlled trials (RCTs) in this field for systematic review and meta-analysis.

We present the following article in accordance with the PRISMA reporting checklist (available at https://dx.doi. org/10.21037/apm-21-2915).

\section{Methods}

\section{Literature search}

(I) Search strategy: the literature search was performed with the search terms ("TCM" or "Chinese traditional medicine" or "Chinese") AND ("stroke") AND ("Gastrointestinal dysfunction" or "Gastrointestinal disorders" or "Gastrointestinal complications" or "constipation" or "vomiting"); (II) Database: we searched the databases of Chinese Biomedical Literature Database (CBM), China National Knowledge Infrastructure (CNKI), Medline, Web of Science; (III) Filter setting: filter setting were made regarding the time of database, literature type, literatures published from January 2010 to August 2021, and all limited to RCTs.

\section{Literature inclusion criteria}

The PICO principle of evidence-based medicine (P: Participant; I: Intervention; C: Control; O: Outcome) was referred to when setting the inclusion criteria: (I) study participants: all patients had been diagnosed with stroke (regardless of ischemic or hemorrhagic stroke), confirmed by brain computed tomography (CT) or magnetic resonance imaging (MRI) imaging, and the symptoms were in accordance with the guidelines for the diagnosis of gastrointestinal disorders after stroke; (II) intervention measures: all studies were divided into control group and experimental group for intervention, the participants of both groups were given post-stroke symptomatic treatment (anticoagulation, blood lipid regulation, vasodilation, nutritional support), the difference between treatment of the patients of the two groups was only in promoting gastrointestinal function, the control group was given conventional western medicine treatment: gastric motility drugs, probiotics, the experimental group was given TCM treatment, including: Chinese medicine decoction, acupuncture, massage, acupressure, external application; (III) Control methods: random grouping method, allocation concealment and blind method; (IV) Outcome measures: the statistical method was complete, clear data could be obtained; including at least 1 of the main outcome measures (effectiveness, bowel sound recovery time, flatulence and defecation time, gastrin level, motilin level, serum albumin, transferrin, prealbumin), and secondary outcome measures (stool character score, gastrointestinal hormones, nutritional indicators).

\section{Literature exclusion criteria}

(I) Intervention participants were non-stroke patients; (II) intervention measures were not clearly described, or western medicine treatment was combined with TCM treatment; (III) there was no clear follow-up time; (IV) outcome indicators were not clearly described, or there was no data; (V) non-RCT. 


\section{Selection of literatures}

After two researchers had independently completed the retrieval, literature data were entered into NoteExpress for subsequent management, repeated studies were filtered out, followed by reading of the title, abstract, and full text of the studies with the proposed inclusion and exclusion criteria, and unqualified articles were excluded. If there was any dispute during this process, a third person was invited to intervene and coordinate after discussion.

\section{Literature risk of bias assessment}

Literature risk of bias was evaluated using the Cochrane review handbook evaluation study: (I) random allocation method; (II) blind method; (III) allocation concealment implementation; (IV) data integrity; (V) selective reporting bias; (VI) other biases, which were evaluated as "low risk", "unclear", and "high risk".

\section{Data extraction and conversion}

After completing the literature selection and bias assessment, the two investigators read the full texts again, from which the characteristic information of the RCTs (author, publication time), participant characteristics (type of stroke, gender ratio, age), information of intervention measures (number of participants in groups, intervention methods) and outcome information (outcome measures) were extracted. For the same indicator, the data expressed in different units in the literatures were uniformly converted into a unit by using the common units in the majority of literatures. If an indicator was predominantly expressed in $\mathrm{mg} / \mathrm{L}$ in the included studies, the remaining data expressed in $\mathrm{mg} / \mathrm{dL}$ or $\mathrm{mol} / \mathrm{L}$ were converted into $\mathrm{mg} / \mathrm{L}$; if the case number data was displayed in $\%$, it was converted into the actual case number.

\section{Statistical analysis}

(I) We used the software Stata 16.0 (Stata Corp. LLC., College Station, TX, USA) for meta-analysis; (II) Continuous indicators were reported using standard mean difference (SMD) effect size and 95\% confidence interval (CI), discrete indicators were reported using odds ratio (OR) effect size and $95 \% \mathrm{CI}$, with $\mathrm{P}<0.05$ indicating statistical significance; (III) Primary outcome indicators were included in the comprehensive analysis, secondary outcome indicators were not included in the comprehensive analysis; (IV) Forest plot was used to display the effect size; (V) $\mathrm{I}^{2}$ analysis and $\mathrm{Q}$ test were used to verify the heterogeneity of literatures, with $\mathrm{I}^{2}>50 \%$ or $\mathrm{P}<0.1$ indicating the existence of heterogeneity, and random effects model was used, otherwise the fixed effects model was used; Mantel-Haenszel model was used for OR effect size, and inverse variance model was used for SMD effect size; (VI) If heterogeneity was suggested between studies, piecemeal exclusion method was used for source analysis, and descriptive analysis was only performed when heterogeneity could not be judged; (VII) Sensitivity analysis was performed on the results; (VIII) Funnel plot was used to indicate publication bias.

\section{Results}

\section{Literature screening process and results}

The document retrieval flow chart is shown in Figure 1, with 216 studies initially retrieved, 16 studies included for selection after screening, and a total of 1,589 patients included.

\section{Basic characteristics of studies}

The basic characteristics, intervention measures, and outcome indicators of the included articles are shown in Table 1, with 7 articles using TCM decoction, 3 using acupuncture, 2 using auricular point pressing beans, 3 using external application of TCM, and 1 article using massage. The indicators of the reports were shown in Table 2.

\section{Literature bias assessment}

In this study, only 9 articles indicated that randomization was used, but the randomization method was unknown; therefore, all articles mentioned classification concealment method; all articles did not adopt the blind method; only 3 articles $(10,15,18)$ mentioned data dropout cases, while the remaining articles did not mention it; indicating no selective reporting or other bias. As shown in Table 3.

\section{Meta-analysis results}

\section{The effective rate}

A total of 9 articles reported the clinical effective rate indicators, including 419 cases in the experimental group and 419 cases in the control group, and 9 articles had no 


\section{Identification of studies via databases and registers}

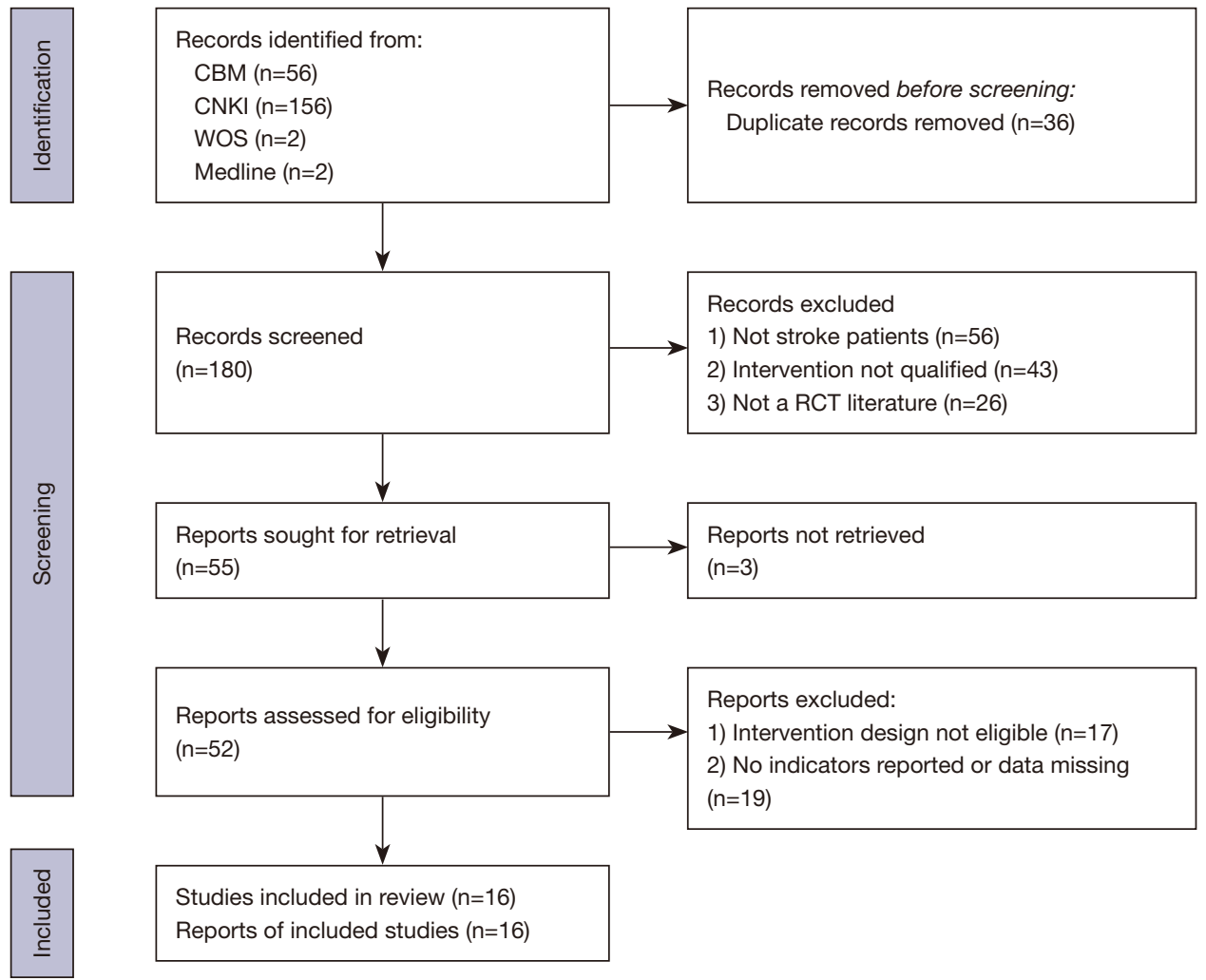

Figure 1 Literature selection flow chart.

Table 1 Basic characteristics, intervention measures, and outcome measures of included studies

\begin{tabular}{|c|c|c|c|c|c|c|c|c|c|}
\hline Author & Year & Stroke type & $\begin{array}{l}\text { Population } \\
\text { (E/C) }\end{array}$ & $\begin{array}{l}\text { Gender ratio } \\
\text { (male:female) } \\
(E / C)\end{array}$ & $\begin{array}{c}\text { Mean age } \\
\text { (years) }(E / C)\end{array}$ & $\begin{array}{l}\text { Intervention method in } \\
\text { the observation group }\end{array}$ & $\begin{array}{l}\text { Intervention } \\
\text { method in } \\
\text { control group }\end{array}$ & $\begin{array}{l}\text { Treatment } \\
\text { course }\end{array}$ & $\begin{array}{l}\text { Outcome } \\
\text { measures }\end{array}$ \\
\hline Long et al. (9) & 2017 & - & $30 / 30$ & $24: 6 / 21: 9$ & $61.60 / 62.13$ & $\begin{array}{l}\text { Auricular pressing } \\
\text { beans, } 4 \text { times/day }\end{array}$ & $\begin{array}{l}\text { Western } \\
\text { medicine } \\
\text { routine }\end{array}$ & 15 days & a \\
\hline
\end{tabular}

Table 1 (continued) 
Table 1 (continued)

\begin{tabular}{|c|c|c|c|c|c|c|c|c|c|}
\hline Author & Year & Stroke type & $\begin{array}{l}\text { Population } \\
\qquad(\mathrm{E} / \mathrm{C})\end{array}$ & $\begin{array}{l}\text { Gender ratio } \\
\text { (male:female) } \\
(E / C)\end{array}$ & $\begin{array}{l}\text { Mean age } \\
\text { (years) (E/C) }\end{array}$ & $\begin{array}{l}\text { Intervention method in } \\
\text { the observation group }\end{array}$ & $\begin{array}{l}\text { Intervention } \\
\text { method in } \\
\text { control group }\end{array}$ & $\begin{array}{l}\text { Treatment } \\
\text { course }\end{array}$ & $\begin{array}{l}\text { Outcome } \\
\text { measures }\end{array}$ \\
\hline Cao et al. (13) & 2014 & $\begin{array}{l}\text { Cerebral } \\
\text { infarction, } \\
\text { cerebral } \\
\text { hemorrhage }\end{array}$ & $90 / 90$ & 62:28/70:20 & $63.00 / 65.00$ & $\begin{array}{l}\text { Houpu exhaust } \\
\text { mixture, } 3 \text { doses/day }\end{array}$ & $\begin{array}{l}\text { Western } \\
\text { medicine } \\
\text { routine }\end{array}$ & 14 days & a \\
\hline Wu et al. (15) & 2014 & $\begin{array}{l}\text { Cerebral } \\
\text { infarction, } \\
\text { cerebral } \\
\text { hemorrhage }\end{array}$ & $40 / 40$ & $22: 18 / 24: 16$ & $67.82 / 68.11$ & $\begin{array}{l}\text { Tuina, every other day, } \\
20 \mathrm{~min} / \text { time }\end{array}$ & $\begin{array}{l}\text { Western } \\
\text { medicine } \\
\text { routine }\end{array}$ & 42 days & $\begin{array}{c}\mathrm{b} / \mathrm{c} / \mathrm{d} / \mathrm{e} / \mathrm{f} / \\
\mathrm{g} / \mathrm{h}\end{array}$ \\
\hline Gu et al. (16) & 2018 & $\begin{array}{l}\text { Cerebral } \\
\text { infarction }\end{array}$ & $58 / 58$ & - & - & $\begin{array}{l}\text { Xiangsha Liujunzi } \\
\text { decoction, } 1 \text { dose/day, } \\
\text { divided into } 2 \text { doses }\end{array}$ & $\begin{array}{l}\text { Western } \\
\text { medicine } \\
\text { routine }\end{array}$ & 10 days & $f / g$ \\
\hline Lu et al. (17) & 2020 & Ischemic & $60 / 60$ & $31: 29 / 34: 26$ & $60.54 / 59.68$ & $\begin{array}{l}\text { Xiangsha Pingwei } \\
\text { decoction, } 1 \text { dose/day, } \\
\text { divided into } 2 \text { doses }\end{array}$ & $\begin{array}{l}\text { Western } \\
\text { medicine } \\
\text { routine }\end{array}$ & 14 days & $a / b / c / d / e$ \\
\hline $\begin{array}{l}\text { Chen et al. } \\
(20)\end{array}$ & 2012 & $\begin{array}{l}\text { Ischemic, } \\
\text { hemorrhagic }\end{array}$ & $79 / 78$ & $51: 28 / 49: 29$ & $58.40 / 57.70$ & $\begin{array}{l}\text { Acupuncture } \\
\text { treatment, once a day }\end{array}$ & $\begin{array}{l}\text { Western } \\
\text { medicine } \\
\text { routine }\end{array}$ & 7 days & b \\
\hline Tang et al. (21) & 2014 & $\begin{array}{l}\text { Ischemic, } \\
\text { Hemorrhagic }\end{array}$ & $48 / 48$ & 28:20/26:22 & $62.40 / 64.60$ & $\begin{array}{l}\text { TCM plaster + TCM } \\
\text { enema }\end{array}$ & $\begin{array}{l}\text { Western } \\
\text { medicine } \\
\text { routine }\end{array}$ & 7 days & $\mathrm{b} / \mathrm{c}$ \\
\hline Zhou et al. (22) & 2018 & $\begin{array}{l}\text { Ischemic, } \\
\text { Hemorrhagic }\end{array}$ & $40 / 40$ & $24: 16 / 25: 15$ & $69.87 / 70.50$ & $\begin{array}{l}\text { Acupuncture at } \\
\text { Zusanli, } 20 \mathrm{~min} / \text { time, } \\
\text { once a day }\end{array}$ & $\begin{array}{l}\text { Western } \\
\text { medicine } \\
\text { routine }\end{array}$ & 30 days & $a / b / c / d / e$ \\
\hline
\end{tabular}

E represents the intervention group and $\mathrm{C}$ represents the control group. a, effective rate; $b$, bowel sound recovery time; $c$, defecation exhaust recovery time; d, gastrin level; e, motilin levels; f, serum albumin; g, transferrin; h, serum prealbumin; TCM, traditional Chinese medicine. 
Table 2 Statistics of included literatures for main indicators

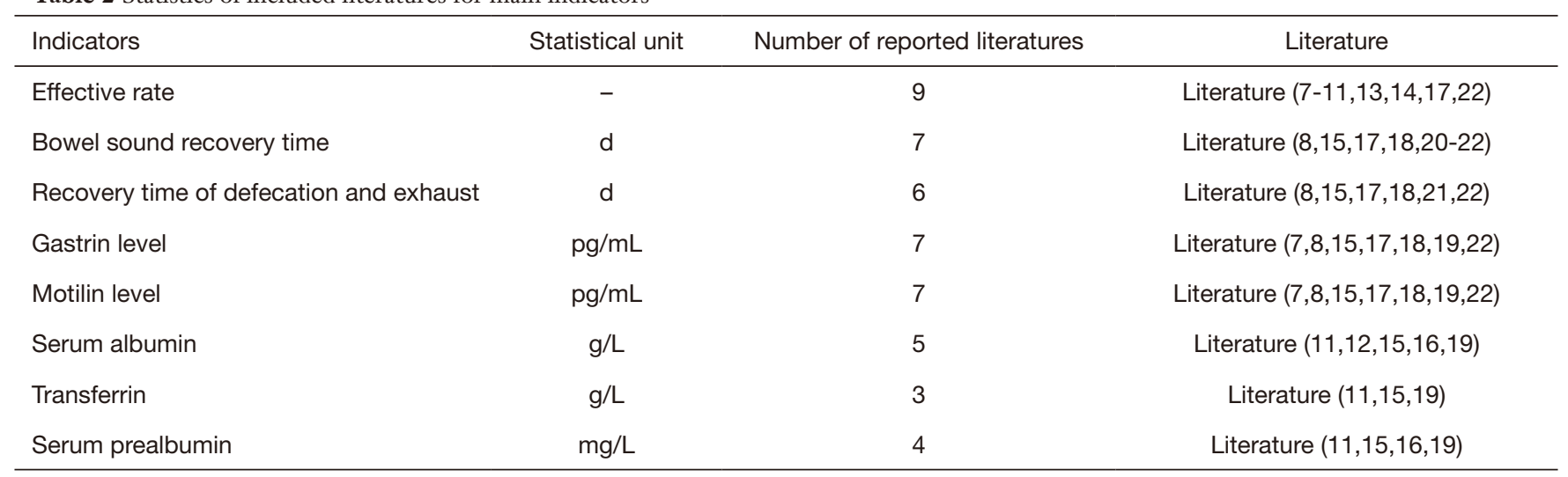

Table 3 Risk of bias assessment based on Cochrane Collaboration

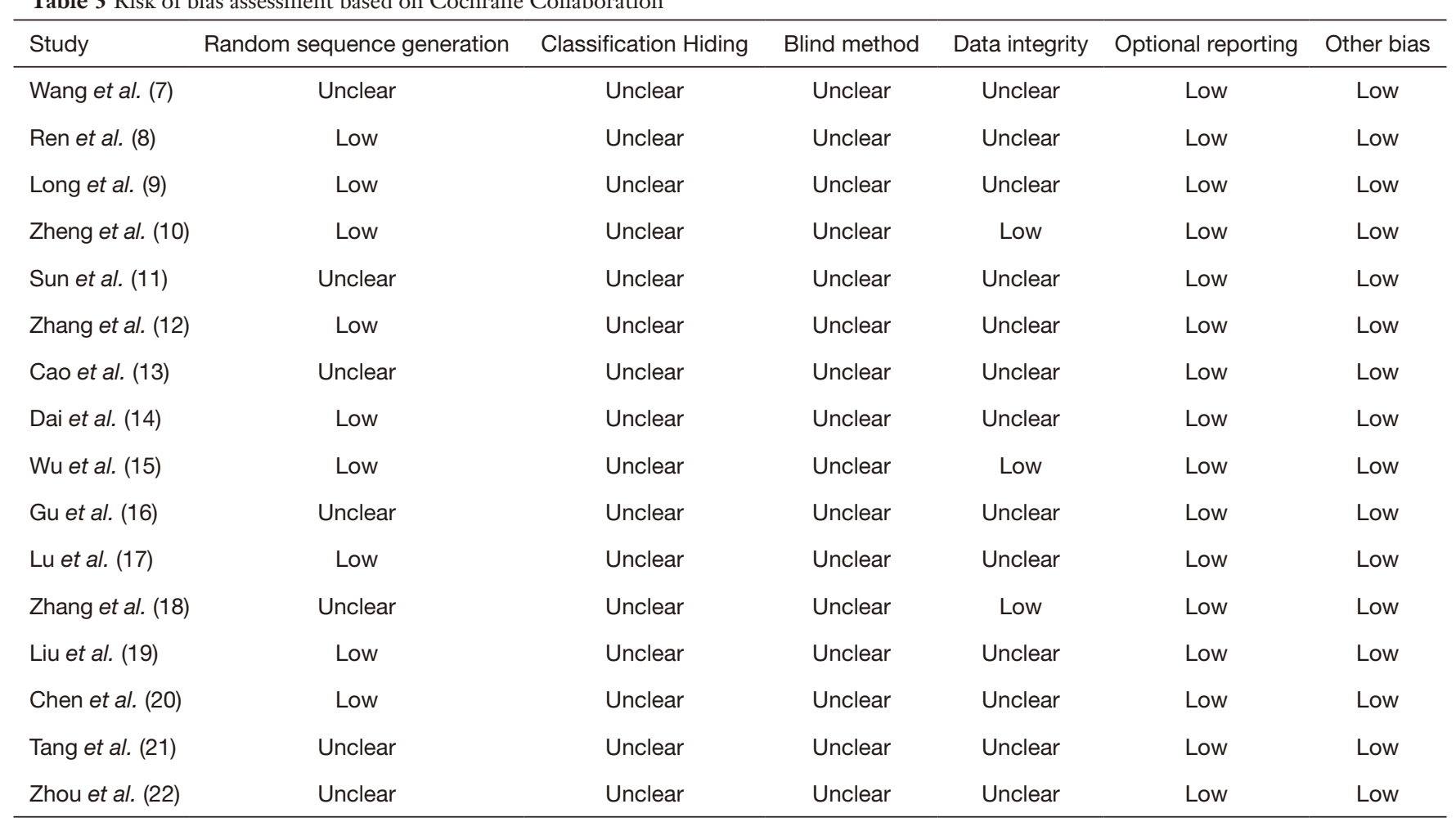

statistical heterogeneity $\left(\mathrm{I}^{2}=0 \% ; \mathrm{P}=0.607\right)$. Only 3 articles $(10,15,18)$ mentioned participants dropping out, so there may have been reporting bias. Using the fixed-effects model analysis, the pooled OR statistic value was 3.94, 95\% CI: 2.63 to 5.89 , indicating that the TCM method was more effective than conventional western medicine in the treatment of gastrointestinal disorders after stroke, with statistical significance $(\mathrm{Z}=6.661 ; \mathrm{P}=0.000)$, as shown in Figure 2.

\section{Bowel sound recovery time}

A total of 7 articles reported the bowel sound recovery time indicators, including 358 cases in the experimental group and 357 cases in the control group. There was statistical heterogeneity in 7 articles $\left(\mathrm{I}^{2}=90.7 \% ; \mathrm{P}=0.000\right)$. Using random-effects model analysis, the combined SMD statistic value was $-1.92,95 \%$ CI: -2.51 to -1.34 , with statistical significance $(Z=-6.439 ; \mathrm{P}=0.000)$, indicating that $\mathrm{TCM}$ in treatment of gastrointestinal disorders after stroke can 


Study (Year)
Wang LL et al. (7) (2017)
Ren XQ et al. (8) (2018)
Long XN et al. (9) (2017)

Figure 2 Combined analysis of the effective rate of traditional Chinese medicine in the treatment of gastrointestinal disorders after stroke $(7-11,13,14,17,22)$.

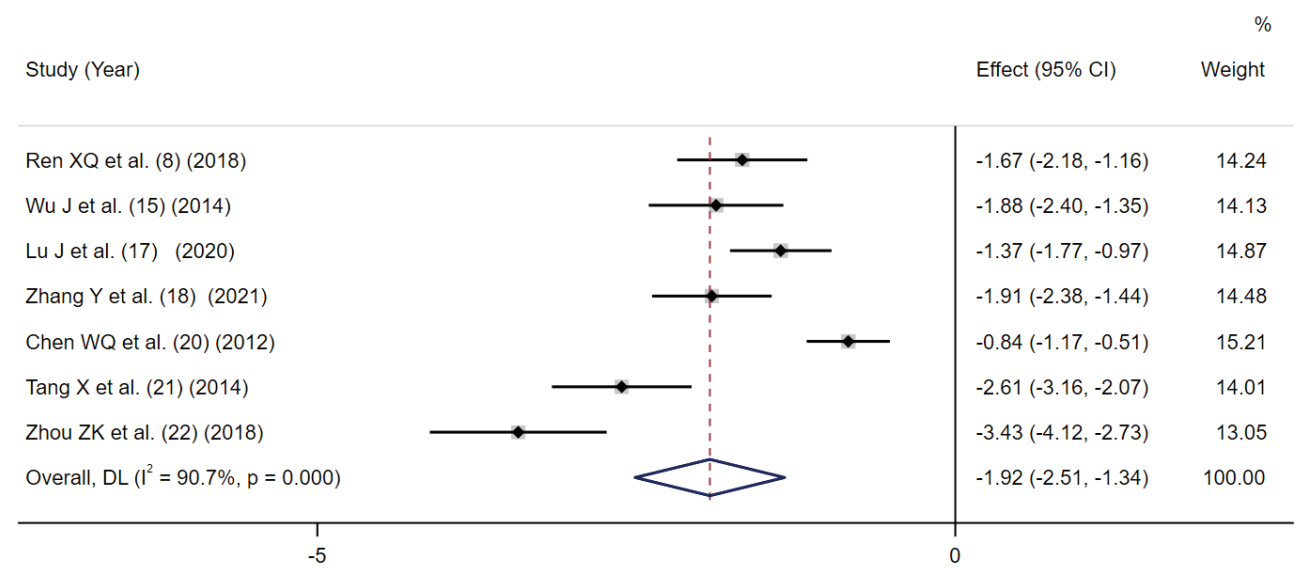

Figure 3 Combined analysis of effect size of bowel sound recovery time $(8,15,17,18,20-22)$.

reduce the recovery time of bowel sounds and it is superior to conventional western medicine, as shown in Figure 3.

\section{Defecation and flatulence recovery time}

A total of 6 articles reported the flatulence and defecation recovery time indicators, including 279 cases in the experimental group and 279 cases in the control group. There was statistical heterogeneity in 6 articles $\left(\mathrm{I}^{2}=93.9 \%\right.$; $\mathrm{P}=0.000)$. Using the random-effects model analysis, the combined SMD statistic value was $-2.51,95 \% \mathrm{CI}:-3.41$ to -1.61 , with statistical significance $(Z=-5.460 ; P=0.000)$, indicating that TCM in the treatment of gastrointestinal disorders after stroke can reduce the defecation and flatulence recovery time and it is superior to conventional western medicine, as shown in Figure 4.

\section{Gastrin level}

A total of 7 articles reported gastrin level indicators, including 325 cases in the experimental group and 325 cases in the control group. There was statistical heterogeneity in 7 articles $\left(\mathrm{I}^{2}=86.7 \% ; \mathrm{P}=0.000\right)$. Using the random-effects model analysis, the pooled SMD statistic value was 0.80 , 


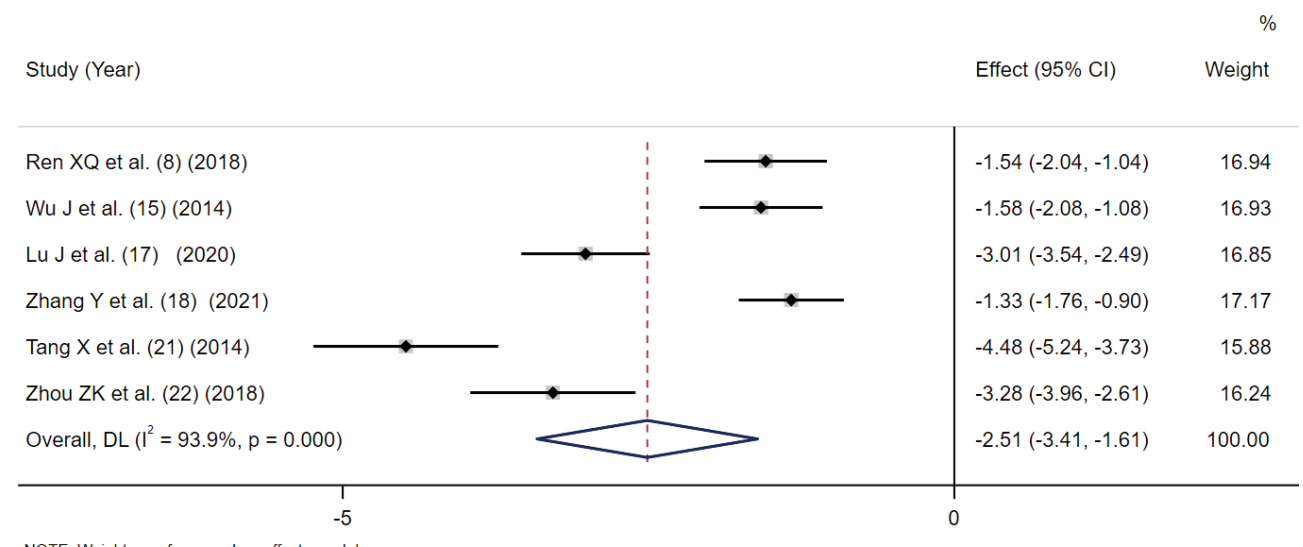

NOTE: Weights are from random-effects model

Figure 4 Combined analysis of effect size of recovery time of exhaust and defecation $(8,15,17,18,21,22)$.

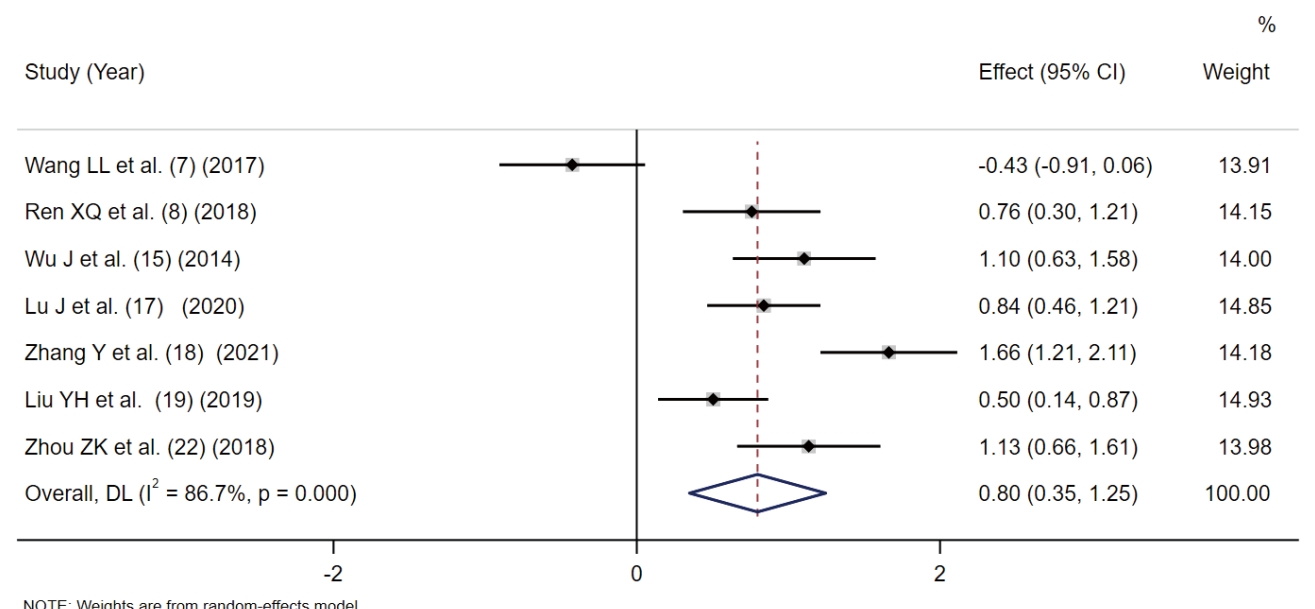

Figure 5 Combined analysis of effect size on gastrin level $(7,8,15,17-19,22)$.

95\% CI: 0.35 to 1.25 , with statistical significance $(Z=3.477$; $\mathrm{P}=0.001$ ), indicating that the treatment of gastrointestinal disorders after stroke with TCM can increase gastrin level and it is better than conventional western medicine, as shown in Figure 5.

\section{Motilin level}

A total of 7 articles reported motilin level indicators, including 325 cases in the experimental group and 325 cases in the control group. There was statistical heterogeneity in 7 articles $\left(\mathrm{I}^{2}=92.5 \% ; \mathrm{P}=0.000\right)$. Random effects model analysis was used to obtain the combined SMD statistic value of $2.27,95 \%$ CI: 1.55 to 3.00 , with statistical significance $(\mathrm{Z}=6.132 ; \mathrm{P}=0.000)$, indicating that $\mathrm{TCM}$ in treatment of gastrointestinal disorders after stroke can increase motilin level and is better than conventional western medicine, as shown in Figure 6.

\section{Serum albumin level}

A total of 5 articles reported serum albumin level indicators, including 241 cases in the experimental group and 241 cases in the control group. There was no statistical heterogeneity in 5 articles $\left(\mathrm{I}^{2}=0.0 \% ; \mathrm{P}=0.956\right)$. The fixed effect model analysis showed that the combined SMD statistic value was $0.72,95 \%$ CI: 0.54 to 0.90 , with statistical significance $(\mathrm{Z}=7.655 ; \mathrm{P}=0.000)$, indicating that TCM in treatment of gastrointestinal disorders after stroke can increase serum albumin level and is better than conventional western 


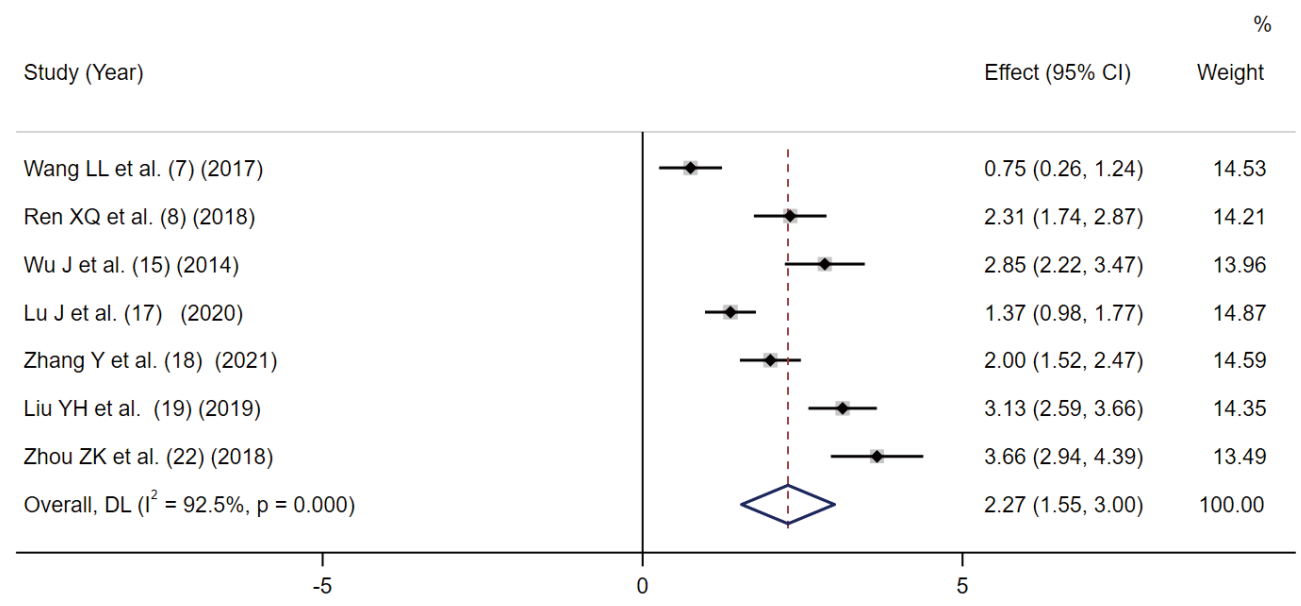

NOTE: Weights are from random-effects model

Figure 6 Combined analysis of effect size of motilin level $(7,8,15,17-19,22)$.

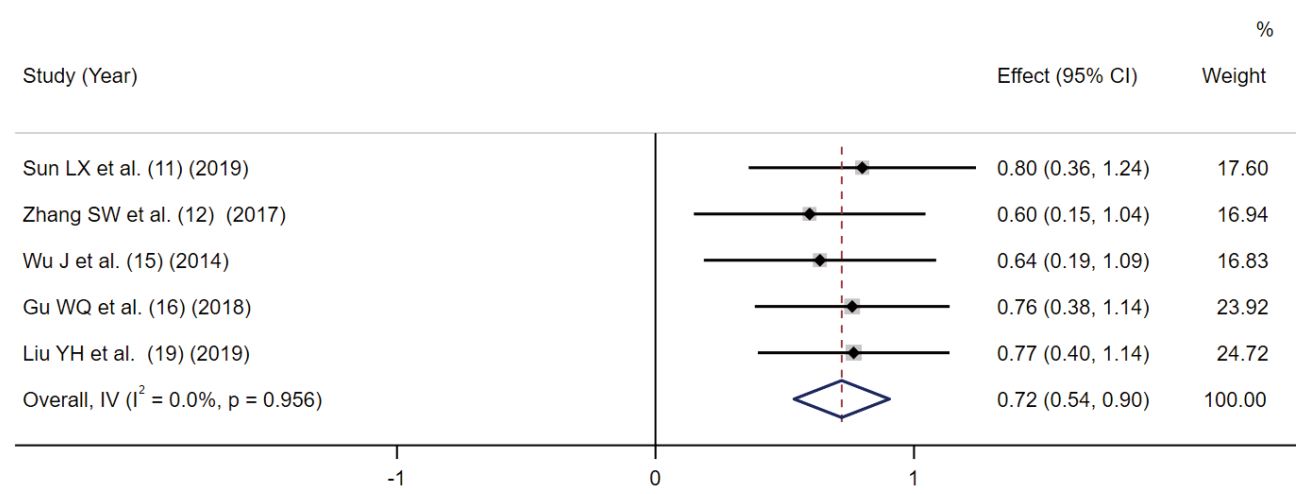

Figure 7 Combined analysis of effect size of serum albumin level $(11,12,15,16,19)$.

medicine, as shown in Figure 7.

\section{Transferrin level}

A total of 3 articles reported transferrin level indicators, including 143 cases in the experimental group and 143 cases in the control group. There was no statistical heterogeneity in 3 articles $\left(\mathrm{I}^{2}=5.3 \% ; \mathrm{P}=0.348\right)$. The fixed effect model analysis showed that the combined SMD statistic value was 1.11 , $95 \%$ CI: 0.86 to 1.36 , with statistical significance $(\mathrm{Z}=8.434$; $\mathrm{P}=0.000$ ), indicating that TCM in treatment of gastrointestinal disorders after stroke can increase transferrin level and is better than conventional western medicine, as shown in Figure 8.

\section{Serum prealbumin level}

A total of 4 articles reported serum prealbumin level indicators, including 201 patients in the experimental group and 201 patients in the control group. There was statistical heterogeneity in 4 articles $\left(\mathrm{I}^{2}=90.1 \% ; \mathrm{P}=0.000\right)$. $\mathrm{T}$ random effects model analysis obtained the pooled SMD statistic value of $1.50,95 \%$ CI: 0.78 to 2.22 , with statistical significance $(\mathrm{Z}=4.080 ; \mathrm{P}=0.000)$, indicating that TCM in treatment of gastrointestinal disorders after stroke can increase serum prealbumin level and is better than conventional western medicine, as shown in Figure 9.

\section{Sensitivity analysis}

Sensitivity analysis on effectiveness indicators showed that 9 articles were evenly distributed and had good stability, as shown in Figure 10.

\section{Analysis of publication bias}

As the number of included articles for all indicators was 


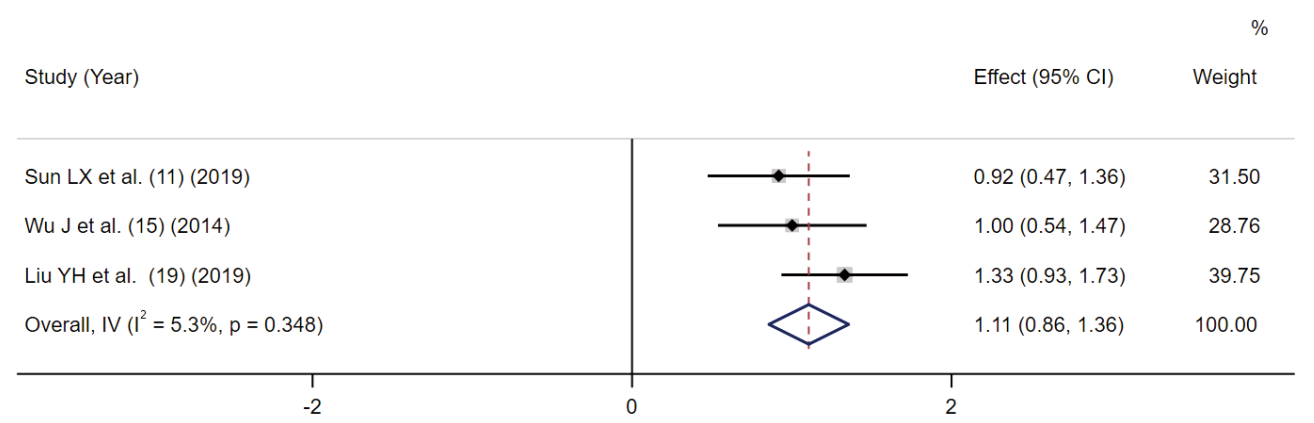

Figure 8 Combined analysis of transferrin level effect size $(11,15,19)$.

\begin{tabular}{l} 
Study (Year) \\
Sun LX et al. (11) (2019) \\
Wu J et al. (15) (2014) \\
Gu WQ et al. (16) (2018) \\
Liu YH et al. (19) (2019) \\
Overall, DL (I $\left.{ }^{2}=90.1 \%, p=0.000\right)$ \\
\hline \\
NOTE: Weights are from random-effects model
\end{tabular}

Figure 9 Combined analysis of effect size of serum prealbumin $(11,15,16,19)$.

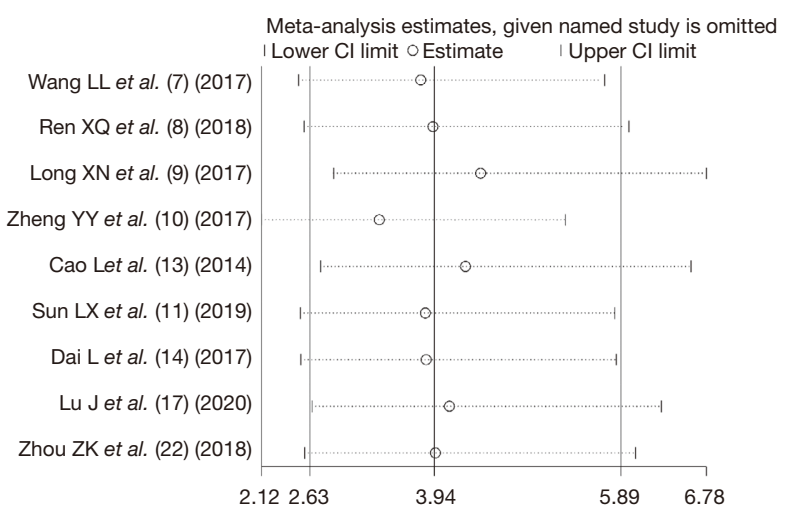

Figure 10 Sensitivity analysis plots for efficacy indicators $(7-11,13,14,17,22)$.

small, no publication bias analysis was performed.

\section{Discussion}

Gastrointestinal dysfunction frequently occurs within
2 weeks after stroke and is a common secondary complication of stroke. Its pathogenesis is that the nervous system is involved in the regulation of gastrointestinal digestive motility and endocrine function. After stroke, the brain function is impaired and the regulation of the nervous system on the gastrointestinal tract is weakened, resulting in kinetic changes and endocrine disorders in the gastrointestinal tract, resulting in symptoms such as vomiting and constipation (23). In addition, patients need to remain in bed for prolonged periods after stroke, have reduced motility, and have diminished gastrointestinal peristalsis, which are also factors contributing to gastrointestinal disturbances (24).

The history of TCM treatment of gastrointestinal disorders is long, and 16 relevant RCTs were included in this systematic review. The results of meta-analysis showed that: (I) TCM treatment (TCM decoction, massage, acupuncture, external application) was more effective than western medicine treatment and could more quickly reduce the symptoms of gastrointestinal disorders; 
(II) TCM treatment restored bowel sound response as soon as possible and shortened the first defecation and flatulence time in stroke patients compared with western medicine; (III) TCM treatment can promote the secretion of gastrin and motilin and is better than conventional western medicine for this purpose; (IV) TCM treatment can improve serum nutritional indicators and is better than conventional western medicine in this regard. Herbal components in TCM decoctions such as Atractylodes lancea, Citrus sinensis, Citrus aurantium, Cyperus rotundus, and Glycyrrhiza uralensis can regulate the stomach and intestines, eliminate abdominal distension, regulate gastrointestinal motility, improve bacterial balance, facilitate the formation of gastrointestinal barrier, and promote their functional recovery; TCM upholds that acupoints (e.g., Zusanli/ST36) are closely related to the secretory function and motor function of the gastrointestinal tract on the basis of long-term observation, and the use of acupuncture and moxibustion to stimulate acupoints can promote gastrointestinal peristalsis, enhance digestion, and improve absorption function; in addition, massage of special acupoints and application of TCM preparations can also play a role in activating blood circulation (25).

The study (12) adopted the treatment method of traditional Chinese medicine decoction combined with nasogastric tube enteral nutrition support, and stated that the decoction mainly regulates the liver and stomach qi machine, strengthens the spleen and stomach, clears phlegm and heat, reduces stomach qi, can significantly improve the symptoms of vomiting, reflux, gastric distention and abdominal distention, cooperate with enteral nutrition support, stimulate gastrointestinal peristalsis and hormone secretion, and can prevent stress ulcer, Protect gastrointestinal mucosal barrier and reduce the colonization of pathogenic bacteria.

A study conducted by Zhang (26) concluded that TCMs combined with routine treatment affect the blood lipid by regulating the contents of TC, TG, LDL, and HDL, and are beneficial to the rehabilitation of patients in the recovery period of apoplexy.

The study (21) pointed out that the treatment of traditional Chinese medicine can not only increase gastrointestinal peristalsis, but also effectively inhibit the proliferation and growth of harmful bacteria, reduce endotoxin and various inflammatory mediators, so as to reduce inflammatory reaction and protect gastrointestinal tissues.
In this study, 16 included articles had operation biases such as unknown randomization method, undescribed allocation concealment, no blind method implemented, and no statistical drop-out cases reported, which may have a certain impact on the results. In the analysis of indicators such as bowel sound recovery time, there was a large heterogeneity between the articles, which may be related to the different types, characteristics, and differences in TCM intervention methods of patients included in the studies. In future studies, more highquality articles need to be included to yield stronger evidence.

\section{Conclusions}

The use of TCM in the treatment of gastrointestinal dysfunction after stroke can effectively reduce symptoms, shorten the recovery time of bowel sounds, the first defecation and flatulence time, promote gastric motility and gastrointestinal hormone secretion, and improve the nutritional status of patients. However, due to the low quality of the included literatures, more highquality clinical RCTs are needed to provide more robust evidence.

\section{Acknowledgments}

Funding: The study was funded by Hainan Health Industry Scientific Research project, project number: 20A200450.

\section{Footnote}

Reporting Checklist: The authors have completed the PRISMA reporting checklist. Available at https://dx.doi. org/10.21037/apm-21-2915

Conflicts of Interest: All authors have completed the ICMJE uniform disclosure form (available at https://dx.doi. org/10.21037/apm-21-2915). The authors have no conflicts of interest to declare.

Ethical Statement: The authors are accountable for all aspects of the work in ensuring that questions related to the accuracy or integrity of any part of the work are appropriately investigated and resolved.

Open Access Statement: This is an Open Access article distributed in accordance with the Creative Commons 
Attribution-NonCommercial-NoDerivs 4.0 International License (CC BY-NC-ND 4.0), which permits the noncommercial replication and distribution of the article with the strict proviso that no changes or edits are made and the original work is properly cited (including links to both the formal publication through the relevant DOI and the license). See: https://creativecommons.org/ licenses/by-nc-nd/4.0/.

\section{References}

1. Martino R, Foley N, Bhogal S, et al. Dysphagia after stroke: incidence, diagnosis, and pulmonary complications. Stroke 2005;36:2756-63.

2. Camara-Lemarroy CR, Ibarra-Yruegas BE, GongoraRivera F. Gastrointestinal complications after ischemic stroke. J Neurol Sci 2014;346:20-5.

3. Roth WH, Cai A, Zhang C, et al. Gastrointestinal Disorders and Risk of First-Ever Ischemic Stroke. Stroke 2020;51:3577-83.

4. Joundi RA, Martino R, Saposnik G, et al. Predictors and Outcomes of Dysphagia Screening After Acute Ischemic Stroke. Stroke 2017;48:900-6.

5. Black CJ, Drossman DA, Talley NJ, et al. Functional gastrointestinal disorders: advances in understanding and management. Lancet 2020;396:1664-74.

6. Xiang H, Sun J, Tang X, et al. The effect and optimal parameters of repetitive transcranial magnetic stimulation on motor recovery in stroke patients: a systematic review and meta-analysis of randomized controlled trials. Clin Rehabil 2019;33:847-64.

7. Wang LL, Xue XF. Clinical observation of Dachaihu Decoction in the treatment of gastrointestinal dysfunction in patients with severe stroke. Modern traditional Chinese Medicine 2017;37:37-9.

8. Ren XQ, Wang MC, Wang HM. Clinical observation of electroacupuncture at Zusanli on gastrointestinal dysfunction after stroke. Chinese Journal of Stroke 2018;13:155-8.

9. Long $\mathrm{XN}$, Liu LM. Observation on the efficacy of bean embedding in ear points in the treatment of constipation after stroke. Journal of Anhui University of traditional Chinese Medicine 2017;36:50-2.

10. Zheng YY, Lin SP, Chen LL. Effect of pressing beans at ear points on gastrointestinal complications in elderly patients with severe enteral nutrition. Medical Theory and Practice 2017;30:2012-3.

11. Sun LX, Song XF. Clinical study on combined abdominal acupuncture with traditional Chinese medicine Reyanbao in the treatment of post-stroke constipation. New Traditional Chinese Medicine 2019;51:245-8.

12. Zhang SW, Zhou Z, Shan LL, et al. Effect of Ganwei Baihe Decoction on enteral nutrition, gastrointestinal complications and nutritional status of stroke patients. Journal of Traditional Chinese Medicine 2017;32:2464-8.

13. Cao L. Clinical efficacy of Houpu exhaust mixture in the treatment of gastrointestinal dysfunction after stroke hemiplegia. Northern Pharmacy 2014;11:23.

14. Dai L. Clinical efficacy of modified Zhizhu Decoction in the treatment of acute stroke complicated with gastrointestinal dysfunction. Inner Mongolia Traditional Chinese Medicine 2017;36:24.

15. Wu J, Wang JJ, Li YG. Value of massage in the treatment of gastrointestinal dysfunction after stroke. Chinese General Medicine 2014;12:457-9.

16. Gu WQ, Sun YL, Zhang SL, et al. Observation on the prevention and treatment of gastrointestinal complications caused by enteral nutrition in patients with severe stroke with Xiangsha Liujunzi Decoction. Clinical Research of Traditional Chinese Medicine 2018;10:39-41.

17. Lu J, Huang MQ. Clinical study of Xiangsha Pingwei Decoction in the adjuvant treatment of gastrointestinal dysfunction after ischemic stroke. International Journal of Traditional Chinese Medicine 2020;42:1102-6.

18. Zhang Y, Li F, Jin WF. Effect of acupoint application combined with massage on postoperative gastrointestinal function of stroke patients. New Traditional Chinese Medicine 2021;53:205-7.

19. Liu YH, Chen W, Gao YG, et al. Clinical efficacy of Yunpi Huotan Tongnao formula in the treatment of gastrointestinal dysfunction after stroke. Guangxi Medical Journal 2019;41:499-501.

20. Chen WQ. Clinical observation on early acupuncture in preventing gastrointestinal dysfunction in patients with acute stroke. Massage and Rehabilitation Medicine 2012;3:10-12.

21. Tang $X$, Zhang XN, Wu WG, et al. Application of traditional Chinese medicine to umbilicus combined with traditional Chinese medicine enema in the treatment of 48 cases of gastrointestinal dysfunction in ICU stroke patients. Hunan Journal of Traditional Chinese Medicine 2014;30:51-3.

22. Zhou ZK. Clinical observation on Electroacupuncture at Zusanli point to restore gastrointestinal function in stroke patients. Journal of Zhejiang University of Traditional 
Chinese Medicine 2018;42:401-3.

23. Cohen DL, Roffe C, Beavan J, et al. Post-stroke dysphagia: A review and design considerations for future trials. Int J Stroke 2016;11:399-411.

24. Schaller BJ, Graf R, Jacobs AH. Pathophysiological changes of the gastrointestinal tract in ischemic stroke. Am J Gastroenterol 2006;101:1655-65.

25. Rabitti S, Giovanardi CM, Colussi D. Acupuncture and
Related Therapies for the Treatment of Gastrointestinal Diseases. J Clin Gastroenterol 2021;55:207-17.

26. Zhang X, Zhang XF, Wang L, et al. Analysis of Clinical Efficacy of Traditional Chinese Medicine in Recovery Stage of Stroke: A Systematic Review and Meta-Analysis. Cardiovasc Ther 2020;2020:7172052.

(English Language Editor: J. Jones)

Cite this article as: Wang YX, Wang LT, Huang ZW, Li TL, Ouyang XF. Effectiveness of traditional Chinese medicine in treating gastrointestinal dysfunction in patients with acute stroke: a systematic review and meta-analysis of 16 randomized controlled trials. Ann Palliat Med 2021;10(11):11808-11820. doi: 10.21037/apm-21-2915 